\title{
How is communication of vaccines in traditional media: a systematic review
}

\section{Authors}

Daniel Catalan-Matamoros Department of Journalism and Communication, University Carlos III of Madrid, Calle Madrid, 133, 28903 Getafe, Madrid, Spain

Research Group of Health Sciences CTS-451, University of Almeria, Almeria, Spain Email: dacatala@hum.uc3m. es

\section{Carmen Peñafiel-Saiz}

Department of Journalism, University of the Basque Country, Spain

\section{Corresponding author:} Daniel Catalan-Matamoros, as above

\section{Keywords}

vaccination; mass media; newspapers; public health; journalism

\section{Abstract}

Aim: Taking into account that a key determinant in public approval of vaccinations is how the media constructs and frames messages about vaccination programmes, our aim is to review communication studies exploring media coverage of vaccines within traditional media venues.

Methods: Using a registered protocol (PROSPERO: 42017072849), a systematic review was conducted that searched in three international electronic databases (PubMed, Scopus, and the International Bibliography of Social Science) for articles published between 2007 and 2017 following content-analysis methods. The characteristics and outcomes were systematically identified and described. The search yielded 24 eligible studies that were further analysed in the review.

Results: Media coverage of vaccines has been largely studied during the last decade. Findings revealed that $62 \%(n=15)$ of studies analysed the human papillomavirus vaccine, $87 \%(n=21)$ examined newspapers, and $62 \%(n=15)$ examined North American media. In relation to media content analyses, $75 \%$ found negative messages on vaccines and $83 \%$ identified a lack of accurate information.

Conclusions: This systematic review suggests an agenda for further research. There is a significant need to analyse other types of traditional media beyond newspapers. Future studies should focus on other geographical areas such as low-income countries and on analysing visual materials and digital media. We found that negative messages and inaccurate information are common in media coverage on vaccines; therefore, further research focusing on these topics is needed. Officials in public health organizations should develop a close collaboration with the media to improve public communication on vaccines.

\section{INTRODUCTION}

The media has been considered an important tool for communicating information about vaccines and increasing awareness and motivating the public ${ }^{1}$ to make important decisions about their health care. ${ }^{2,3}$ Traditional media coverage and the rapid growth of the Internet and social media such as Twitter and Facebook have made it easier to find and disseminate immunizationrelated concerns and misperceptions. ${ }^{4}$ These concerns have also been raised by the former WHO Director General Margaret Chan who expressed anxieties over what she called a 'worrisome' public mistrust of vaccines. ${ }^{5} \mathrm{~A}$ clear example can be found in measles, which is one of the leading causes of death among young children even though a safe and cost-effective vaccine is available. According to the $\mathrm{WHO},{ }^{6}$ in
2015, there were 134,200 measles deaths globally - about 367 deaths every day, or 15 deaths every hour. There has been widespread uncertainty regarding the exact science particularly when the media tries to provide a 'balanced' view, giving at least equal space and time to anti-vaccinationists even though, for example, more than $99 \%$ of informed medical and health-related professionals fully support the vaccine against measles, mumps, and rubella $(\mathrm{MMR}) .^{7}$ When the media covers information on vaccines, journalists usually cover multiple sides of an issue and provide insight into where strong evidence lies by focusing on 'evidentiary balance'.8

The vaccine media debate has been raging for many years; immunizations have a long and complicated history of both saving lives and 
Search strategy in PubMed

\section{Search terms}

Items found

$\# 1$

Search [Title] mass media OR communications media OR television OR radio OR newspaper OR 18041 print OR magazine OR journal OR book OR pamphlet OR cinema OR movie OR news Filter: 2007/01/01 - 2017/01/01

hurting them. Parental acceptance of routine childhood immunization is essential to protecting children's health. ${ }^{3}$ But maintaining that acceptance can be difficult, especially because the success of immunization programmes has resulted in new generations of parents who have little or no first-hand experience with most of the diseases that are preventable by vaccination. ${ }^{3}$ In addition, some events involving vaccines have diminished trust. For example, in 1998, a scientist claimed there might be a link between the MMR vaccine and autism. His claims received significant media attention, and vaccination rates fell in many countries, although many scientific experts asserted that there was no scientific evidence that the MMR vaccine played any part in the aetiology or triggering of autism. ${ }^{9}$ Therefore, vaccine adherence is becoming an increasingly challenging public health issue.

Media content published by journalists may impact public perception on preventive health measures and influence decisions on the public's well-being. In some cases, the role of the media has been shown to contribute to promoting harmful health behaviours. ${ }^{10}$ It has been known that societal dynamics, including the introduction of new health practices, is partly mediated by mass media. ${ }^{11}$ Given that communication via the media is a common practice, it is important to explore how the media represents vaccines. For example, a key determinant in the approval of vaccination with the public will be how the media constructs and frames messages about vaccination programmes. ${ }^{10}$
Despite the growth of digital media, we have decided to focus our review on traditional media sources in order to narrow and synthesize this paper. 'Traditional media', according to previous studies, ${ }^{12,13}$ includes television, radio, newspapers, magazines, medical journals, books, pamphlets, and movies - or in other words, any form of mass communication available before the advent of digital media. ${ }^{14}$ Moreover, traditional media sources are not dead and still play an important role in the communication landscape. ${ }^{15}$ In fact, traditional media outlets have been in existence for a long time and remain a central medium of communication in many regions of the world. Some examples of what sources report high newspaper readership levels ${ }^{16}$ include USA Today (estimated daily readership of 9.6 million in 2017) and The New York Times (estimated readership 9.3 million in 2017). Moreover, in the US, traditional media outlets are accessed more than digital media: $6 \mathrm{~h}$ and 16 min per day versus $5 \mathrm{~h}$ and 50 min per day, respectively. ${ }^{17}$ In some countries like Sweden, newspapers are highly consumed by society. ${ }^{18}$ Therefore, this article conducts a systematic review to identify communication research regarding traditional media coverage of vaccines and describes their characteristics and outcomes. We addressed the following research questions in relation to the contents about vaccines in traditional media sources:

1. What countries have been assessed?

2. What communication channels have been analysed?
3. What vaccines have been analysed most frequently?

4. What are the most relevant measures and outcomes found in the selected studies?

\section{METHODS}

This systematic review was registered with PROSPERO: CRD42017072849.

The development of this systematic review was guided by the PRISMA statement. ${ }^{19,20}$ Literature search strategies were developed using medical subject heading (MESH) and text words related to mass media. Search strategies combined two types of terms: 'vaccine' (e.g. vaccine, vaccination, immunization) and 'traditional media outlets' (e.g. television, radio, newspaper; see search strategy in Table 1). We searched three databases: PubMed, which comprises more than 28 million citations for biomedical literature from MEDLINE, life science journals, and online books; Scopus, which is considered the largest abstract and citation database of peerreviewed literature from the science, technology, medicine, social sciences, and arts and humanities fields; and The International Bibliography of Social Sciences (IBSS), which is a central online resource for social science and interdisciplinary research including over two million bibliographic references to journal articles, books, and reviews. Papers that were written in English and published between 1 January 2007 and 1 January 2017 were included. We chose the time period from 2007 to search for studies made after the publication of the WHO guidelines on the safety of medicines, in which mass 
Figure

PRISMA flow diagram.

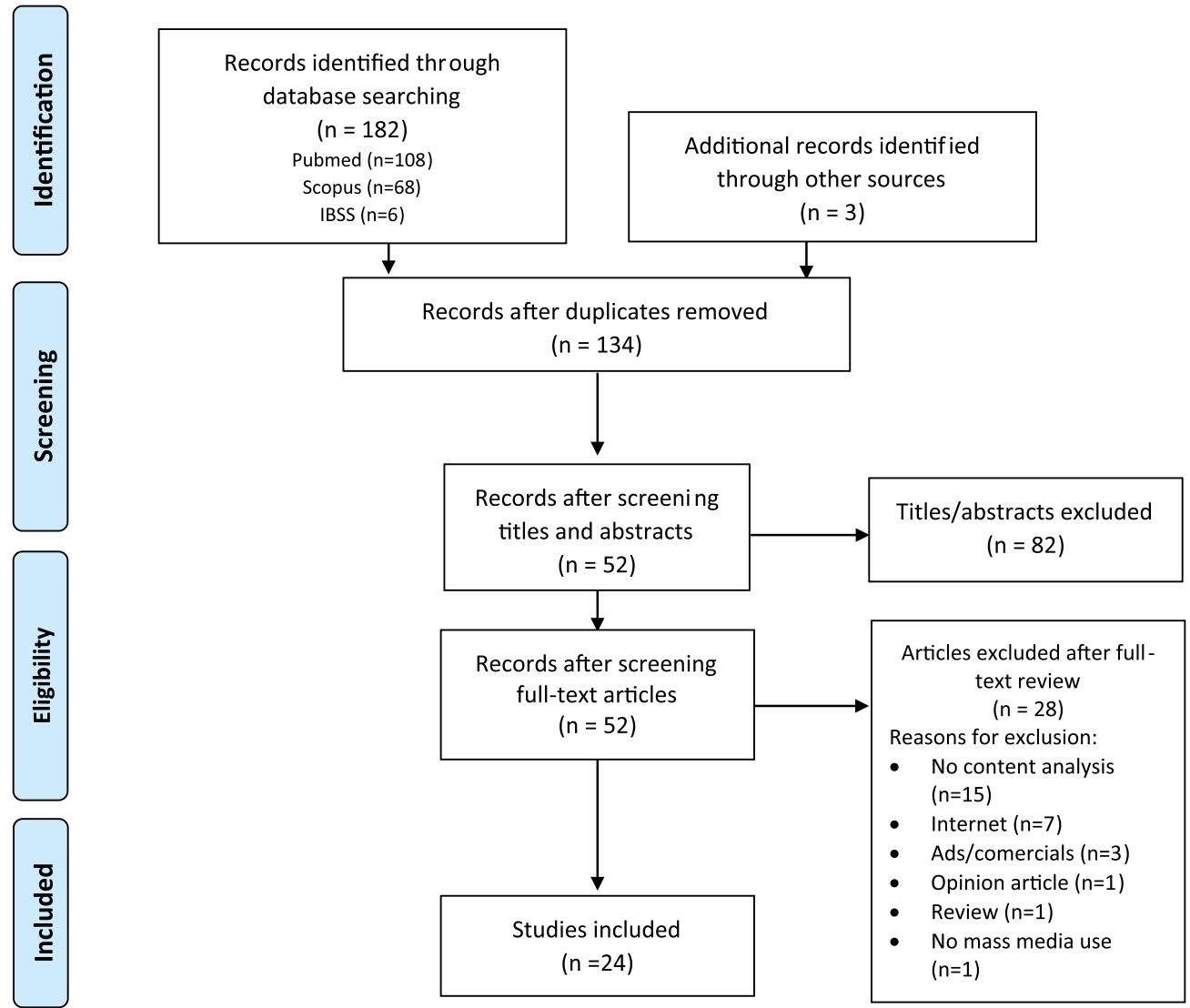

media was recognized as a key element. ${ }^{21}$ In addition, during this period, there was a decrease in childhood vaccination rates, which may have been supported by some media debates on the safety of the human papillomavirus (HPV) vaccine and the relationship between autism and the MMR vaccine.

Regardless of their methodological quality, studies had to meet the following inclusion criteria: (1) conduct a content analysis of publications made in a traditional mass media source such as radio, television, newspapers, or any other outlet such as movies; (2) address vaccines or immunization; and (3) report original qualitative or quantitative data examining the media coverage of vaccines. We searched content-analysis articles as this research method is considered the most frequent in media coverage research. ${ }^{22}$ Reference lists of key articles were manually searched to identify further relevant studies.
Systematic reviews, abstracts, dissertations, single case reports, editorials, commentaries, conference abstracts, non-research articles, and studies that focused on digital mass media such as websites or social networks were excluded. Articles analysing advertisements on vaccines in the media were also excluded.

The PRISMA flow diagram in Figure 1 outlines the screening processes applied to the articles identified by the literature searches that were subsequently screened for duplication and relevance using titles and abstracts. Of those, articles that were considered relevant were assessed for eligibility by reviewing full texts.

Literature search results were uploaded to Zotero to facilitate bibliographic source management. Following the removal of duplicates, two independent reviewers screened the titles and abstracts according to eligibility criteria. A third researcher was consulted when necessary. All researchers involved in the review were 'health communication' scholars educated in communication sciences and public health. All discrepancies between reviewers were resolved through discussion and full agreement was reached. We obtained full articles for all titles that appeared to meet the inclusion criteria or where there was an uncertainty. The appropriateness of the full-text papers was verified to check that they met the eligibility criteria.

The review team developed a coding form designed to capture descriptive information on the included studies. The variables were as follows: country where the media were broadcasted, media type, vaccine type, objectives, main variables, sample size, main outcomes, and conclusions. We synthesized data qualitatively, dividing studies into vaccine types. Findings from mapping and 
analysis were recorded in data extraction tables and summarized as narrative answers to the research questions. We did not focus on media effects to consider a meta-analysis, and we did not conduct a quality assessment of studies since all met the inclusion criteria for following the same research methodology (i.e. content analysis). Overall, the aims, data collection methods, samples, and outcomes were sufficiently well-described in the studies in terms of having a good understanding of the study and being able to identify relevant information to be included in our review.

\section{RESULTS}

The screening processes identified 182 articles resulting from the literature search and were subsequently screened for duplication and relevance. In addition, three relevant articles ${ }^{10,23,24}$ were identified by manually searching in reference lists. After duplicates were removed, we reviewed titles and abstracts from 134 articles. Of those, 52 full-text articles were considered relevant and assessed for eligibility. A total of 28 full-text articles were excluded after careful review. The specific reasons for exclusion can be found in Figure 1. This ultimately led to the inclusion of 24 studies for further analysis. For a summary of characteristics of the 24 studies, please see Table 2. For a summary of measures, outcomes, and conclusions, please see Table 3 (see Supplementary online material). Mentions and short descriptions of all analysed references have been included in Tables 2 and 3 where readers can search for deeper information beyond the one presented in our review. We summarized below the main findings for each of the four research questions.

\section{RQ1: What countries have been assessed?}

Among the 24 studies, 15 studies analysed North American media, 11 from the US and four from Canada. Four studies analysed UK media and two studies analysed New Zealand media. The following countries' media were also analysed: Australia $(n=1)$, Japan $(n=1)$,
Nigeria $(n=1)$, Romania $(n=1)$, and the United Arab Emirates $(n=1)$. The majority of studies analysed media from one single country; only two studies analysed media from more than one country. ${ }^{24,28}$ Dr. Casciotti's team published the highest amount of articles during the period of analysis $(n=3)$. Dr. Casciotti's affiliation was with the Department of Health, Behaviour, and Society at the Johns Hopkins Bloomberg School of Public Health in Baltimore, MA (USA). This authorship finding is consistent with our finding that the US was the leading country investigating media coverage about vaccines.

\section{RQ2: What communication channels have been analysed?}

Print media, especially newspapers, were the most frequent media type reported among the included studies. In total, $96 \%$ ( $n=23$ ) of all studies reported print media, and of those, $87 \%(n=21)$ explored coverage by newspapers. Other studies analysing print media were on magazines $(n=1)$, and a combination of media sources including newspapers, magazines, and videos $(n=1)$. Only one study $(n=1)$ analysed coverage by television, and another study included a survey administered to individuals. The 24 studies comprised 8628 units of media content analyses: 8529 newspaper articles, 59 television and video broadcasts, and 40 magazine articles. The average study sample size was 152 units of analysis ( $S D=479.34$; range 15-2113). One study included a survey administered to 4367 individuals. Most of the studies analysed media targeting general audiences or readerships. For example, studies made in the US frequently analysed large newspapers such as USA Today and The New York Times.

\section{RQ3: What vaccines have been analysed most frequently?}

The most common vaccine that was analysed in the selected studies was the human papillomavirus vaccine (HPV; $62 \%, n=15)$. Three studies analysed the MMR and the controversy about its relationship to autism. Two studies analysed the influenza vaccine (seasonal and $\mathrm{A} / \mathrm{H} 1 \mathrm{~N} 1$ ), and one article analysed the polio vaccine. Three articles did not analyse one specific vaccine.

RQ4: What are the most relevant measures and outcomes found in the selected studies?

In relation to the measures, all articles described the characteristics of media coverage quantitatively, such as the frequency of target contents, number of pages, word count, dates of publication length, and so on. After this quantitative description of the sample, the main variables varied according to the aims of each study. Some common measures were sources of information, message characteristics (i.e. tone, controversy, risks, barriers, concerns, support to vaccination, health outcomes), completeness, and use of evidence concerning vaccination.

The outcomes that were found in each of the studies have been grouped as: 'messages analysis', 'accuracy and evidence-based information', and 'other outcomes'. In relation to message analysis, $50 \%$ of the studies ( $n=12$ ) analysed messages in relation to vaccines. Of these, $83 \%$ of the studies ( $n$ $=10$ ) found more negative messages than positive ones and mostly focused on vaccines being negative, ineffective, poorly understood by science, and causing harm. Seventeen percent $(n=2)$ of articles found positive messages in relation to vaccines and vaccination. Of these, one study found more messages supporting the vaccination of $\mathrm{A} / \mathrm{H} 1 \mathrm{~N} 1$ than reasons against getting vaccinated. ${ }^{38}$ The other study found that most articles were positive in tone, prompted by research and scientific advancement or legislative activities. ${ }^{26}$

In relation to accuracy and evidencebased information, these studies analysed whether public information on vaccines was based on scientific clinical trials or other scientific studies. Thirtythree percent of the studies $(n=8)$ analysed the accuracy and completeness of the information provided and if journalists provided evidence-based information. Of these, $75 \%(n=6)$ found a lack of accuracy. More specifically, an 
Table 2.

\section{Characteristics of the selected studies}

\begin{tabular}{|c|c|c|c|c|}
\hline Authors & Country & Media type & Vaccine & Objectives \\
\hline $\begin{array}{l}\text { Abdelmutti and } \\
\text { Hoffman-Goetz }\end{array}$ & Canada & Magazines & HPV & $\begin{array}{l}\text { Assess the discussion of risks, fear-inducing messages about } \\
\text { HPV, cervical cancer, and the HPV vaccine }\end{array}$ \\
\hline Casciotti et al. ${ }^{26}$ & US & Newspapers & HPV & $\begin{array}{l}\text { Understand media portrayal of vaccine-related controversy, } \\
\text { and potential influences on attitudes and vaccine acceptance }\end{array}$ \\
\hline Casciotti et al. ${ }^{27}$ & US & Newspaper & HPV & $\begin{array}{l}\text { Examine media coverage of HPV vaccine mandates during } \\
\text { 2005-2009 }\end{array}$ \\
\hline Casciotti et al. ${ }^{1}$ & US & Newspapers & HPV & $\begin{array}{l}\text { Examine US news media messages related to sexuality and } \\
\text { HPV vaccination }\end{array}$ \\
\hline Clarke 28 & US and UK & Newspapers & MMR & $\begin{array}{l}\text { Look at normative pressures that may influence whether } \\
\text { mobilizing information appears in media coverage }\end{array}$ \\
\hline $\begin{array}{l}\text { Cooper Robbins, Pang, } \\
\text { and Leask, } 2012\end{array}$ & Australia & Newspaper & HPV & $\begin{array}{l}\text { Establish a comprehensive picture of how Australian media } \\
\text { portrayed HPV vaccine and its surrounding issues }\end{array}$ \\
\hline $\begin{array}{l}\text { Elbarazi, Raheel, } \\
\text { Cummings, and Loney, } \\
2016\end{array}$ & $\begin{array}{l}\text { United Arab } \\
\text { Emirates }\end{array}$ & Newspapers & HPV & $\begin{array}{l}\text { Explore the content and communication style of the UAE } \\
\text { newspapers (both Arabic and English) before, during, and after } \\
\text { the HPV vaccination programme. }\end{array}$ \\
\hline Goodyear-Smith et al. ${ }^{29}$ & $\begin{array}{l}\text { New } \\
\text { Zealand }\end{array}$ & Newspapers & Not specific & $\begin{array}{l}\text { Analyse the content of written media in } 2001 \text { and } 2003 \\
\text { throughout NZ in terms of vaccination and vaccine preventable } \\
\text { diseases from a supporting, neutral, or opposing perspective; } \\
\text { how vaccination and vaccine-preventable diseases are } \\
\text { presented to their target audiences; and changes over time } \\
\text { with possible influences on these changes }\end{array}$ \\
\hline Guillaume and Bath30 & UK & Newspapers & MMR & $\begin{array}{l}\text { Analyse the mass media coverage that the MMR (measles, } \\
\text { mumps and rubella) vaccine received as a result of questions } \\
\text { raised about its safety }\end{array}$ \\
\hline Hilton et al. ${ }^{10}$ & UK & Newspapers & HPV & $\begin{array}{l}\text { Examine the role the newsprint media have played in HPV } \\
\text { advocacy by identifying key messages about the risks and } \\
\text { benefits associated with HPV vaccination and HPV infection, } \\
\text { and how these stories were constructed and framed for } \\
\text { different readership groups }\end{array}$ \\
\hline Holton et al. ${ }^{24}$ & $\begin{array}{l}\text { UK, US and } \\
\text { others }\end{array}$ & Newspapers & MMR & $\begin{array}{l}\text { (1) Analyse actors to which the news media attributed blame } \\
\text { for the controversy along with sources used to do so , (2) } \\
\text { explore coverage over time, taking into account potential } \\
\text { changes in attribution, and (3) assess attributions of } \\
\text { responsibility for addressing this issue and its effects, focusing } \\
\text { on mobilizing information provided to readers }\end{array}$ \\
\hline Hussain et al. ${ }^{31}$ & US & Newspapers & Not specific & Identify and describe vaccine safety in US newspaper articles \\
\hline Kelly et al. ${ }^{23}$ & US & $\begin{array}{l}\text { Newspapers } \\
\text { and survey }\end{array}$ & HPV & $\begin{array}{l}\text { Explore the nature of the coverage of HPV and whether } \\
\text { knowledge about HPV was affected by this coverage }\end{array}$ \\
\hline $\begin{array}{l}\text { Krakow and Rogers, } \\
2016\end{array}$ & US & Newspapers & HPV & $\begin{array}{l}\text { Examines a pivotal time period for public health in which the } \\
\text { vaccine became officially recommended for boys and men and } \\
\text { at the same time became the centre of political controversies in } \\
\text { the lead-up to the } 2012 \text { presidential campaign }\end{array}$ \\
\hline
\end{tabular}


Table 2 (Continued)

\section{Characteristics of the selected studies}

\begin{tabular}{|c|c|c|c|c|}
\hline Authors & Country & Media type & Vaccine & Objectives \\
\hline Meyer et al. ${ }^{32}$ & Canada & Newspaper & Seasonal flu & $\begin{array}{l}\text { Identify the nature of the relationship between risk messages } \\
\text { about getting the seasonal flu vaccine in newspaper coverage } \\
\text { and the uptake of the vaccine }\end{array}$ \\
\hline Olufowote 33 & Nigeria & Newspapers & Polio & $\begin{array}{l}\text { Understanding of the role of fragmentation in global health } \\
\text { initiatives through analyses of } 52 \text { northern Nigerian newspaper } \\
\text { reports of the } 2003-2004 \text { northern Nigerian stoppage of the } \\
\text { Global Polio Eradication Initiative }\end{array}$ \\
\hline Penta and Baban ${ }^{34}$ & Romania & $\begin{array}{l}\text { Newspapers, } \\
\text { magazines and } \\
\text { videos. }\end{array}$ & HPV & $\begin{array}{l}\text { Explore the content and quality of HPV vaccine media } \\
\text { coverage in Romania }\end{array}$ \\
\hline Perez et al. ${ }^{35}$ & Canada & Newspapers & HPV & $\begin{array}{l}\text { Investigated what information about the HPV vaccine was } \\
\text { relayed to the public, and how this content was portrayed } \\
\text { following the } 2012 \text { male HPV vaccine recommendation }\end{array}$ \\
\hline Petousis-Harris et al. ${ }^{36}$ & $\begin{array}{l}\text { New } \\
\text { Zealand }\end{array}$ & Newspapers & Not specific & $\begin{array}{l}\text { Explore New Zealand's four major daily newspapers' coverage } \\
\text { of immunisation with regards to errors of fact and fallacy in } \\
\text { construction of immunisation-related arguments }\end{array}$ \\
\hline $\begin{array}{l}\text { Quintero Johnson } \\
\text { et al. }{ }^{37}\end{array}$ & US & Newspapers & HPV & $\begin{array}{l}\text { Examine the news information presented about the HPV } \\
\text { vaccine in major US newspapers over the } 19 \text { months following } \\
\text { its Food and Drug Administration (FDA) approval. }\end{array}$ \\
\hline Rachul et al. ${ }^{38}$ & Canada & Newspapers & $\mathrm{A} / \mathrm{H} 1 \mathrm{~N} 1$ & $\begin{array}{l}\text { Analyse Canadian newspapers' portrayal of the } \mathrm{A} / \mathrm{H} 1 \mathrm{~N} 1 \\
\text { vaccine including mention of risks and benefits of the vaccine } \\
\text { and whether the article supported, questioned or was neutral } \\
\text { about the vaccine. }\end{array}$ \\
\hline $\begin{array}{l}\text { St John, Pitts, and } \\
\text { Tufts, } 2010\end{array}$ & US & Newspapers & HPV & $\begin{array}{l}\text { Explore how both the news media and parents framed and } \\
\text { responded to the newly mandated HPV vaccine }\end{array}$ \\
\hline Tsuda et al. ${ }^{39}$ & Japan & Newspapers & HPV & $\begin{array}{l}\text { Evaluate the characteristics of newspaper publications about } \\
\text { human papillomavirus vaccination }\end{array}$ \\
\hline $\begin{array}{l}\text { Wallace and Ache, } \\
2009\end{array}$ & US & TV & HPV & $\begin{array}{l}\text { Examine the content of human papillomavirus (HPV)-related } \\
\text { vaccination information presented during nightly national } \\
\text { television news broadcasts }\end{array}$ \\
\hline
\end{tabular}

A/H1N1: subtype of influenza A virus; HPV: human papilloma virus; MMR: mumps, measles, rubella (vaccine).

article found that evidence-based information supporting claims for or against getting vaccinated appeared in only $27.8 \%$ and $6.8 \%$ of the articles, respectively. ${ }^{38}$ Other studies found a lack of comprehensive information, inaccuracies, and detailed coverage of HPV and the HPV vaccine. Other studies identified numerous mistakes in both fact and logic predominantly used by antiimmunisation proponents but occasionally by health authorities. ${ }^{36}$ One article found sources overwhelmingly supplied opinions rather than facts. ${ }^{24}$ One article found messages prompted by research and scientific studies. ${ }^{26}$

Finally, the studies also focused on 'other outcomes'. Three studies identified sources that were used by journalists. 24,30,37 They found that the content and format of articles between different information sources varied widely, with government/political sources, medical doctors, and the US Centres for Disease Control and Prevention (CDC) being the most commonly cited sources. Only $16 \%$ of all articles featured personal accounts. Two additional recent studies looked at the lack of vaccine information for the HPV vaccine targeting boys and men. ${ }^{35,40}$ The studies described that the majority of articles (93\%) mentioned that girls are eligible for the HPV vaccine, 
whereas only half (49\%) mentioned male eligibility. While most articles associated HPV with cervical cancer (85\%), fewer indicated its relation to other HPVassociated cancers (59\%) or genital warts (52\%). One study stated that key political events might have functioned to overshadow the recommendation of the HPV vaccine for boys and men. Another study analysed the relationship between vaccination rates and media coverage of the flu vaccine. ${ }^{32}$ Vaccination rates were positively and significantly related to the frequency of risk messages in newspaper coverage $(r=.691, p<.05)$. Finally, a study 28 found that the educational level required for best readability of the media content was higher than recommended for the general public.

\section{DISCUSSION}

The present systematic review provides an overview of the communication research on traditional media coverage about vaccines. The objective of this study was to identify communication research on traditional media coverage in relation to vaccines and to describe the characteristics and outcomes. To our knowledge, this is the largest systematic review of media content analysis on vaccines, composed of 27 studies published during the last 10 years (since 2007) covering public communication of any type of vaccine by traditional media sources from any geographical region. There are some main findings that can be drawn from this systematic review.

First, the 24 studies tackle a broad array of vaccines. The majority of the studies included in this review originated from North America (11 from the US and 4 from Canada), and in clearly lower proportions from other high-income countries such as the UK, New Zealand. Australia, Japan, and the United Arab Emirates. Only two countries that are actually not classified as high-income countries according to the World Bank, ${ }^{41}$ have been analysed. These were Nigeria and Romania. There could be several reasons for the lack of publications in low-income countries. These may include limited technical competency in scientific writing, lack of research, high teaching burden at universities (which does not allow time for research and writing), and biases against low-income countries' authors by journal editors, editorial boards, and publishers from high-income countries. ${ }^{42}$ In addition, there is also a lack of funding from international funding agencies, which are largely from developed nations, and many journals from low-income nations are not indexed in global databases; 43 thus, they could not be found through our systematic review. A reason for the dominance of research in the US might be because of the established regulatory system for direct-to-consumer prescription drug advertising (DCTA). In fact, DTCA of prescription drugs is illegal in some countries as a health protection measure but is permitted in the US and New Zealand. ${ }^{44}$ The advertising of overthe-counter (OTC) products and dietary supplements to consumers is allowed in these countries and in others. Therefore, there is an increasing need for analyses of public communication about vaccines in other geographical groups such as low-income countries, because laws regarding this communication on medicines are rarely implemented in these countries due to lack of commitment and resources on the part of law enforcement departments. ${ }^{45}$ According to our systematic review, the characteristics and outcomes of media coverage for vaccines in low-income countries is almost currently unknown from a research perspective.

Regarding the methodological approach of the selected studies, this systematic review showed a preference for conducting media coverage analyses in print media, including both newspapers and magazines. Bundling these two media sources into one category might be too general; however, we decided to do so, although we should highlight that newspapers were the most frequent media source among the analyses. Only one study examined TV coverage. This is consistent with a previous review ${ }^{46}$ where newspapers were the most analysed media. However, this homogeneous analysis does not reflect the real mass media consumption by the public. For example, US adults now spend $12 \mathrm{~h}$ a day consuming media, from which print media represents only $25 \mathrm{~min}$, TV represents 4 $\mathrm{h}$, and radio represents almost $1.5 \mathrm{~h} .{ }^{17}$ The dominance of print media in our sample reflects the preferences for media research: newspapers are most frequently sampled by social scientists over other media sources, ${ }^{47}$ as it could be more convenient to analyse printed information than other types of audiovisual media. Further research should focus on other potential traditional media sources beyond newspapers, such as radio and television.

Regarding the vaccines analysed by the studies that fulfilled our search criteria, the HPV vaccine was the most frequent. There is sizeable literature on HPV vaccines portrayal in the media. $\mathrm{HPV}$ infection is highly prevalent and sexually transmitted with a peak incidence in adolescents and young adults. Chronic HPV infections are the leading cause of cervical dysplasia and cervical cancer. Gardasil, a vaccine directed against HPV, generated both positive and negative media and public attention. Gardasil was implemented among unease about timing and rushed approvals, and questions about its longterm safety and efficacy was voiced by public and health officials. ${ }^{25}$ Other types of vaccines reported on were the influenza vaccine (both seasonal and $\mathrm{A}$ $\mathrm{H} 1 \mathrm{~N} 1)$, the polio vaccine, and the MMR vaccine, but in clearly lower proportions. However, according to the WHO's global immunization coverage programme, ${ }^{48}$ there are other important vaccines with either very low media attention or that have not been analysed by social scientists. These are hepatitis $B$, meningitis A, pneumococcal diseases, rotaviruses, tetanus, and yellow fever. Further content analyses would be needed to explore media coverage of these other important vaccines.

Regarding the outcomes of the media coverage on vaccines, it is possible to draw attention to and address important questions raised in previous content analyses. In relation to messages, this was the most common outcome analysed by the selected studies. Most of the studies found negative messages about vaccines in the media, for example, media sources reported that the vaccine was poorly understood by 
science, was not effective, and that it may cause harm. ${ }^{32}$ In fact, this is not too surprising. According to Taylor, ${ }^{7}$ journalists and editors want a good story and they often do not put much attention to public health. From our view, this is alarming given that the media remain an important source of health information, ${ }^{49}$ and even health officials often view journalists as valuable channels through which to promote the benefits of immunization and communicate risk information. 50 However, the journalistic goal of ensuring an informed citizenry inevitably clashes with the goals of other actors such as health officials, owners of media companies, information sources, and advertisers. These journalistic goals include entertainment (reporting news that is interesting or exciting), profitability (reporting stories that generate revenue and maximize viewership), and favourability (reporting stories that reflect positively on owners). ${ }^{28}$ From a public health perspective, it is critical to provide comprehensive and transparent information in the media for the public to make informed decisions. Information about efficacy, details about the accrual of evidence regarding vaccine safety and efficacy, as well as subsequent implementation of vaccination policies may mitigate perceptions of risk by the public. ${ }^{32}$ However, we should take into account media space constraints that pose challenges to extensive explanations. As previously stated, the analyses of media messages may be considered one of the most relevant areas in the research of public communication about vaccines. Thus, we recommend further research on this specific topic.

Level of accuracy and evidence-based information provided are other key outcomes. Health reporters in particular often rely on information from scientific sources when crafting stories because of the complex nature of many health issues. ${ }^{24}$ According to the selected studies, there is a lack of comprehensive information, inaccuracies, and errors of both fact and logic, concluding that journalists misrepresent the state of clinical evidence. It is particularly important to avoid the transmission of inaccurate information to prevent misinterpretation and wrong decisions about getting vaccinated. It has been considered a useful strategy22,34 to improve communication between health officials and journalists. In fact, when the news media misinform the public, this leads to misperceptions of reality among their audience members and also impacts trust and credibility. Without trust and credibility, people will turn away from the media and consequently seek information from other suppliers. ${ }^{51}$ A key challenge is how to be transparent about inaccuracies or mistakes by journalists to avoid fear and keep the readership trust.

Finally, only two studies looked at behaviour change through analysing the relationship between vaccination rates and media coverage;23,32 therefore, our systematic review did not draw conclusions about the effects of media among citizens due to the lack of studies analysing the relationship between media coverage and public behaviour. If in the future there are more studies, we recommend conducting pooled analyses of the effects of media coverage about vaccines.

Although our review followed systematic review methods, some limitations need to be noted, and any interpretation of the results must take into account the restrictions of the study. First, the findings of the review can only present the distributions as they appear in the journals that were included in our search strategy. Any process involving the selection of journals has unavoidable limits. The inclusion of additional publications in the future is most likely to gradually change the image that has emerged here. Second, our analysis focused only on original scientific studies that have been published, so it is not a comprehensive assessment of media coverage in general. Our study only focused on what samples and approaches researchers have followed in their studies. For example, we are limited in our synthesis to vaccine coverage in other media types. We found that television $(n=1)$ and radio $(n=0)$ were infrequently or not analysed, compared to print media $(n=21)$. Moreover, we are concerned that media consumption today is not the same as before when people waited for their morning papers or sat down at an appointed time for the evening television news. More and more readers, viewers, and listeners are going online for their news. Television, newspapers, and radio are still here, but there is growing competition. ${ }^{52}$ In our systematic review, we did not include studies analysing online social networks (i.e. YouTube, Facebook, or Twitter). Since $88 \%$ of millennials get their news from social media, ${ }^{46}$ this is a limitation in the current study especially for this age group. Third, we only searched for content analyses studies as a research method. Here, we can only speculate on the importance of the messages covered and the information quality, but we cannot claim that the patterns have actually shaped public views or vaccination behaviours. Randomised clinical trials (RCTs) examining media effects are required to make these causal assertions. In fact, according to Boyce, ${ }^{9}$ there is a paucity of research examining journalistic materials and their impact on audience understandings. In spite of these limitations, to our knowledge, this is the largest systematic review to date that analyses media coverage on vaccines. Given the explosion of scientific literature, and the fact that time is always scarce, review articles play a vital role in decision-making and evidence-based practice. Given that most decisionmakers do not have the time to track down all the original articles, critically read them, and obtain the evidence they need for their questions, systematic reviews may be their best source. ${ }^{53}$

Finally, this systematic review includes some practical implications. In line with other authors, ${ }^{28,32}$ our systematic review does not suggest that journalists should become public health practitioners tasked with persuading people to be vaccinated. Rather, media can serve as a resource through which people become aware of an issue, aware of strategies to address this issue, and potentially motivated to take action depending on pre-existing attitudes and predispositions. To achieve this, our systematic review provides a useful basis and will be of interest to those in the health field as well as researchers and policy makers who are trying to communicate their message about 
vaccines to the public. Since the results of the literature review are consensual on the fact that media coverage of medicines comprises of mostly negative messages and inaccurate information that could negatively impact public health initiatives, public health officials implementing vaccination programmes should develop a close collaboration with journalists and the media. Thus, we recommend future research on institutional communication ${ }^{54,55}$ from public health authorities to journalists in order to identify its characteristics and areas for improvement, if any. The communication on the part of public health agencies to stakeholders and the public should also be analysed as it is considered vital. ${ }^{56}$ Another recommendation for future research should focus on online media reviews since they are key in rapidly spreading health messages to society. Finally, further research should also focus on the analysis of visual materials (i.e. photos, graphics, infographics, tables, etc.) included in newspaper articles especially because of the readership that mostly consume headlines and images.

\section{CONCLUSIONS AND PUBLIC HEALTH IMPLICATIONS}

This systematic review shows that coverage of vaccines by traditional media sources is a topic that has been largely studied during the last decade. Most of the studies conducted content analyses in newspapers, and the HPV vaccine was the most frequent selected vaccine by the studies. Moreover, North American national media sources were the most frequent among those selected by researchers. We have identified gaps in the current literature and an agenda for further research. There is a strong need to conduct research on other types of media such as television and radio, address a wider variety of vaccine types, and explore other geographical areas such as low-income countries. We found that negative messages and inaccurate information are common in media coverage on vaccines. Public health officials who deal with vaccines should develop a close collaboration with the media to improve public communication on vaccines.

\section{ACKNOWLEDGEMENTS}

The authors would like to express their gratitude to Dr. Carlos David Santamaría, from the Department of Law and Social Sciences, Autonomous University of Tamaulipas (Mexico), for his support in the article screening process.

\section{CONFLICT OF INTEREST}

The author(s) declared no potential conflicts of interest with respect to the research, authorship, and/or publication of this article

\section{ETHICAL APPROVAL}

Ethical approval is not needed as the study does not involve human subjects.

\section{FUNDING}

This study was supported by the Research Group of Health Sciences CTS-451 at the University of Almeria, Spain.

References

1. Casciotti DM, Smith KC, Tsui A et al. Discussions of adolescent sexuality in news media coverage of the HPV vaccine. $J$ Adolescence 2014;37(2):133-43.

2. Levitan M. Medical journalism in Canada: what audiences learn from public health coverage. Int J Humanit 2011;9(6):87-96.

3. Catalán-Matamoros D. El gran avance del ámbito científico y académico de la comunicación en salud [The great development of the scientific and academic field of health communication]. Rev Esp Comun En Salud 2017;8(2):114.

4. Kennedy A, LaVail K, Nowak G et al. Confidence about vaccines in the United States: understanding parents' perceptions. Health Aff 2011;30(6):1151-9.

5. Chan M. WHO director-general calls for change. Geneva: World Health Organization; 2011. Available online at: http://www.who.int/ dg/speeches/2011/eb_20110117/en/index. $\mathrm{html}$

6. WHO. Immunization, vaccines and biologicals: Measles [Internet], 2017. Available online at: http://www.who.int/immunization/diseases/ measles/en/ (last accessed 26th July 2017).

7. Taylor B. Vaccines and the changing epidemiology of autism. Child Care Health Dev 2006;32(5):511-9.

8. Clarke CE, Dixon GN, Holton A et al. Including 'evidentiary balance' in news media coverage of vaccine risk. Health Commun 2015;30(5):461-72

9. Boyce T. Journalism and expertise. Journalism Stud 2006;7(6):889-906
10. Hilton S, Hunt K, Langan M et al. Newsprint media representations of the introduction of the HPV vaccination programme for cervical cancer prevention in the UK (2005-2008). Soc Sci Med 2010;70(6):942-50.

11. Tulloch JC, Zinn JO. Risk, health and the media. Health Risk Soc 2011;13(1):1-16.

12. Vesa J, van Heck E. Factors in adopting multiaccess technologies in online consumer auction markets in Finland. Eur Manag $J$ 2005;23(2):182-94.

13. Lalazaryan A, Rahimi A, Zare-Farashbandi F et al. How health information is received by diabetic patients? Adv Biomed Res 2015;4(1):126.

14. IGI Global. What is traditional media? IGI global disseminator of knowledge. Available online at: https://www.igi-global.com/dictionary/ traditional-media/47688 (2018, last accessed 12th April 2018).

15. Belch $G$, Belch $M$. The role of new and traditional media in the rapidly changing marketing communications environment. Int J Strateg Innov Mark 2014;1:130-6.

16. Statista. Number of readers. The Statistics Portal. Available online at: www.statista.com (2017, last accessed 21st April 2018).

17. eMarketer. US adults now spend 12 hours 7 minutes a day consuming media. 2017 May 1 Available online at: https://www.emarketer. com/Article/US-Adults-Now-Spend-12-Hours7-Minutes-Day-Consuming-Media/1015775

18. Catalán Matamoros DJ, Axelsson R et al. How do newspapers deal with health in Sweden? A descriptive study. Patient Educ Couns 2007;67(1-2):78-83.
19. PRISMA-P Group, Moher D, Shamseer L et al Preferred reporting items for systematic review and meta-analysis protocols (PRISMA-P) 2015 statement. Syst Rev 2015;4:1. Available online at: http://systematicreviewsjournal. biomedcentral.com/ articles/10.1186/2046-4053-4-1 (last accessed 11 August 2017).

20. Shamseer L, Moher D, Clarke M et al. Preferred reporting items for systematic review and meta-analysis protocols (PRISMA-P) 2015: elaboration and explanation. $B M J$ 2015;349(1):g7647-g7647.

21. WHO. The safety of medicines in public health programmes. World Health Organization. Available online at: http://www.who.int/ medicines/areas/quality_safety/safety_efficacy/ Pharmacovigilance_B.pdf?ua=1 (2006, last accessed 1 December 2017)

22. Macnamara J. Media content analysis: its uses, benefits and best practice methodology. Asia Pac Public Relat J 2005;6(1):1-34.

23. Kelly BJ, Leader AE, Mittermaier DJ et al. The HPV vaccine and the media: how has the topic been covered and what are the effects on knowledge about the virus and cervical cancer? Patient Educ Couns 2009; 77(2): 308-13.

24. Holton A, Weberling B, Clarke CE et al. The blame frame: media attribution of culpability about the MMR-Autism vaccination scare. Health Commun 2012;27(7):690-701.

25. Abdelmutti N, Hoffman-Goetz L. Risk messages about HPV, cervical cancer, and the HPV vaccine Gardasil in North American news 
magazines. J Cancer Educ 2010;25(3): 451-6.

26. Casciotti DM, Smith KC, Klassen AC. Topics associated with conflict in print news coverage of the HPV vaccine during 2005 to 2009. Hum Vacc Immunother 2014;10(12):3466-74.

27. Casciotti DM, Smith KC, Andon L et al. Print news coverage of school-based human papillomavirus vaccine mandates. J Sch Health 2014:84(2):71-81.

28. Clarke CE. A case of conflicting norms? Mobilizing and accountability information in newspaper coverage of the autism-vaccine controversy. Public Underst Sci 2011;20(5):609-26.

29. Goodyear-Smith F, Petousis-Harris H, Vanlaar $\mathrm{C}$ et al. Immunization in the print media perspectives presented by the press. J Health Commun 2007;12(8):759-70.

30. Guillaume L, Bath PA. A content analysis of mass media sources in relation to the MMR vaccine scare. Health Inform $J$ 2008;14(4):323-34.

31. Hussain H, Omer SB, Manganello JA et al. Immunization safety in US print media, 19952005. Pediatrics 2011;127:S100-6.

32. Meyer SB, Lu SK, Hoffman-Goetz L et al. A content analysis of newspaper coverage of the seasonal flu vaccine in Ontario, Canada, October 2001 to March 2011. J Health Commun 2016;21(10):1088-97.

33. Olufowote JO. Local resistance to the global eradication of polio: newspaper coverage of the 2003-2004 vaccination stoppage in Northern Nigeria. Health Commun 2011;26(8):743-53.

34. Penta MA, Baban A. Mass media coverage of HPV vaccination in Romania: a content analysis. Health Educ Res 2014;29(6): 977-92.

35. Perez S, Fedoruk C, Shapiro GK et al. Giving boys a shot: the HPV vaccine's portrayal in Canadian newspapers. Health Commun 2016;31(12):1527-38.

36. Petousis-Harris HA, Goodyear-Smith FA, Kameshwar $\mathrm{K}$ et al. Fact or fallacy? Immunisation arguments in the New Zealand print media. Aust NZ J Publ Heal 2010;34(5):521-6.

37. Quintero Johnson J, Sionean C, Scott AM. Exploring the presentation of news information about the HPV vaccine: a content analysis of a representative sample of U.S. newspaper articles. Health Commun 2011;26(6):491-501.

38. Rachul CM, Ries NM, Caulfield T. Canadian newspaper coverage of the $\mathrm{A} / \mathrm{H} 1 \mathrm{~N} 1$ vaccine program. Can J Public Health/Rev Can Sante Publique 2011;102(3):200-3.

39. Tsuda K, Yamamoto K, Leppold C et al. Trends of media coverage on human papillomavirus vaccination in Japanese newspapers. Clin Infect Dis 2016;63(12):1634-8.

40. Krakow M, Rogers B. Collateral damage and critical turning points: public health implications of HPV vaccine news coverage for boys and men in 2011. Health Commun 2016;31(9):1081-8.

41. Data \& Statistics. World Bank. Available online at: https://data.worldbank.org/indicator/NY. GNP.PCAP.CD?locations=XM-XD-XT-XN (2017, last accessed 28th May 2018).

42. Muula AS. Medical journals and authorship in low-income countries. Croat Med $J$ 2008;49(5):681-3.

43. Marusić A, Sambunjak D, Marusić M. Journal quality and visibility: is there a way out of the scientific periphery? Prilozi 2006;27(1): 151-61.

44. Mintzes B, Morgan S, Wright JM. Twelve years' experience with direct-to-consumer advertising of prescription drugs in Canada: a cautionary tale. PLOS ONE 2009;4(5):e5699.

45. Byarugaba D. Antimicrobial resistance in developing countries and responsible risk factors. Int J Antimicrob Ag 2004;24(2): 105-10.

46. Gollust SE, LoRusso SM, Nagler RH et al. Understanding the role of the news media in HPV vaccine uptake in the United States: synthesis and commentary. Hum Vacc Immunother 2016;12(6):1430-4.

47. Teixeira R, Carlini M, Jatoba-e-Sousa A et al. Reporting on health-related research in two prestigious Brazilian newspapers. Clinics 2012;67(3):261-4.
48. World Health Organization (WHO) Immunization coverage. Geneva: WHO. Available online at: http://www.who.int/ mediacentre/factsheets/fs378/en/ (2017, last accessed 25th July 2017).

49. Vasterman P, Yzermans CJ, Dirkzwager AJE. The role of the media and media hypes in the aftermath of disasters. Epidemiol Rev 2005;27(1):107-14.

50. Leask J, Chapman S. 'The cold hard facts' immunisation and vaccine preventable diseases in Australia's newsprint media 19931998. Soc Sci Med 2002;54(3):445-57.

51. Karlsson M, Clerwall C, Nord L. Do not stand corrected: transparency and users' attitudes to inaccurate news and corrections in online journalism. J Mass Commun $Q$ 2017;94(1):148-67.

52. Alejandro J. Journalism in the age of social media. Oxford: University of Oxford, Reuters Institute for the Study of Journalism; 2010 (Reuters Institute Fellowship Paper). Available online at: https://reutersinstitute.politics.ox.ac. uk/sites/default/files/Journalism\%20in\%20 the\%20Age\%20of\%20Social\%20Media.pdf [last accessed 25th July 2017).

53. Ganeshkumar P, Gopalakrishnan S. Systematic reviews and meta-analysis: understanding the best evidence in primary healthcare. J Fam Med Prim Care 2013;2(1):9.

54. Moreda Sánchez EM, Martínez Pastor E, Vizcaíno Pérez R. Comunicación Institucional Intercultural para la Salud: desarrollo durante la primera década del siglo XXI. Rev Esp Comun EN SALUD 2017;8(1):54

55. Calleja-Reina MA, Díaz Cerveró E, Vázquez Barrio T. Dengue en Corrientes (Argentina): Estrategia de comunicación en Twitter durante el brote de 2016 = Dengue fever in Corrientes (Argentina): Communication strategy in Twitter during the outbreak of 2016. Rev Esp Comun EN SALUD 2017;8(2):118

56. Longest BB, Rohrer WM. Communication between public health agencies and their external stakeholders. J Health Hum Serv Adm 2005;28(2):189-217.

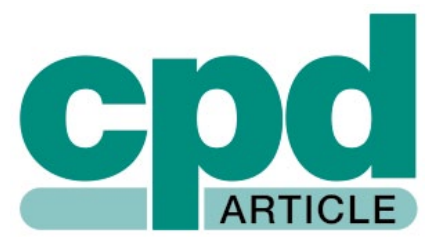

The November CPD paper was 'Attitudes towards smokefree high streets: a survey of local shoppers in a northern UK town' G Brenner, K Mann, D Lee, J Burrows, S Crosby

Answers: b, c, d, b 